\title{
A NOVEL EXPLICIT FINITE DIFFERENCE SCHEME FOR PARTIAL DIFFERENTIAL EQUATIONS
}

\author{
S.K. DEY \\ Eastern Illinois University \\ Charleston, Il. 61920 USA \\ E-mail: cfskd@eiu.edu
}

Received August 23, 1999; revised October 15, 1999

\begin{abstract}
Most explicit finite difference schemes have very stringent stability criterion. In 1982 , Charlie Dey [1] developed a novel method and solved several partial differential equations representing models of fluid flow. (He was then only 10 years old). Recent mathematical analysis shows that this relatively simple method is quite powerful to solve any flow model if it has a steady-state solution using a stability criterion which is a lot less stringent than most explicit finite difference schemes generally applied in Computational Fluid Dynamics $[2]$.
\end{abstract}

\section{INTRODUCTION}

Explicit difference algorithms are some of the simplest extrapolation techniques to solve partial differential equations. Several of these techniques are described in [2]. Lax's method, Leap-frog scheme, Lax-Wendroff algorithm, MacCormack Method, Beam and Warming's upwind method are quite famous. Charlie's algorithm is possibly simpler than all of them. Yet it is quite powerful. In comparison with other extrapolation methods, it demonstrates far better stability property.

In [1] the non-vectorized form of Charlie's algorithm has been discussed. In '94, this algorithm has been represented in a vectorized form [3] and several nonlinear differential equations having steady-state solutions were solved.

We will study the algorithm of this numerical technique, analyze its stability and study solutions of several partial differential equations. 


\section{THE ALGORITHM}

Let us consider an initial-value problem:

$$
\begin{aligned}
& \frac{d u}{d t}=f(u), \\
& u\left(t_{0}\right)=u_{0} .
\end{aligned}
$$

Euler's forward extrapolation formula is:

$$
U_{n+1}=U_{n}+h f\left(U_{n}\right), \quad U_{0}=u_{0},
$$

where $h$ is the time-step and $U_{n}$ is the grid function corresponding to $u\left(t_{n}\right)$. Charlie used (2.2) and added to that a convex corrector. Thus his new algorithm for solving (2.1) numerically is:

Compute:

$$
\begin{array}{ll}
\text { Step\#1 } & \hat{U}=U_{n}+h f\left(U_{n}\right), \\
\text { Step\#2 } & U_{n+1}=(1-\gamma) \hat{U}+\gamma\left\{U_{n}+h f(\hat{U})\right\},
\end{array}
$$

where $0<\gamma<1$. The first step is called the predictor, which is the same as Euler's forward extrapolation formula. The second step is Charlie's corrector. It may be observed that if $\gamma=\frac{1}{2}$, this algorithm reduces to Second Order Runge-Kutta Method. Let us consider the stability analysis. Let

$$
d u / d t=\lambda u, \quad u\left(t_{0}\right)=u_{0} .
$$

The predictor is:

$$
\hat{U}=U_{n}+\lambda h U_{n}
$$

the corrector is:

$$
U_{n+1}=(1-\gamma) \hat{U}+\gamma\left\{U_{n}+\gamma h \hat{U}\right\}
$$

Combining them we get:

$$
U_{n+1}=\sigma U_{n},
$$

where

$$
\sigma=1+\lambda h+\gamma \lambda^{2} h^{2}
$$


The method is strictly stable if

$$
|\sigma|<1
$$

An Example: Let $\lambda=-80$. Then $\sigma=1-80 h+\gamma(-80)^{2} h^{2}$. If $h=0.025$, $|\sigma|=0.6<1$, thus the method is stable.

If $h=0.07,|\sigma|=1.46>1$, the method is unstable. If $h=0.1,|\sigma|=0.6<$ 1 , the method is stable again. This feature of Charlie's algorithm, made it interesting.

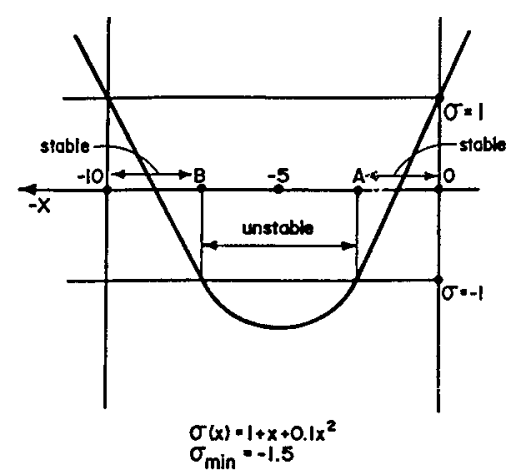

At $A, x=-2.7639$

At $B, x=-7.2361$

Figure 1. The stability curve $\sigma(x)$.

In fig. 1, with $x=\lambda h$, the stability curve, $\sigma(x)=1+x+\gamma x^{2}$ is drawn with $\gamma=0.1$. Here stability is given by $-2.7639 \leq x \leq 0$ and $-10 \leq x \leq-7.2361$. The method is unstable for: $-7.2361 \leq x \leq-2.7639$. If we set $\gamma=0$, stability is given by $-2 \leq x \leq 0$. Thus Charlie's convex corrector has improved the stability property of (2.3) considerably. We will prove the following theorem:

Theorem 2.1. If Charlie's Predictor/Corrector is strictly stable, it must converge to the steady-state solution.

Proof. The initial-value model (2.1), has a solution if $f(u)$ satisfies the Lipschitz condition on $\left[t_{0}, \infty\right)$. Let $D$ be the range of $f(u)$. Then, the criterion for the existence of solution is: $\forall v, w \in D$,

$$
|f(v)-f(w)| \leq L|v-w|
$$

Let $u=U^{*} \in D$ be the steady-state solution. Then $f\left(U^{*}\right)=0$. Obviously,

$$
U^{*}=(1-\gamma) U^{*}+\gamma\left\{U^{*}+h f\left(U^{*}\right)\right\},
$$


subtracting (2.12) from (2.4) we get

$$
\begin{aligned}
\left|U_{n+1}-U^{*}\right| & \leq(1-\gamma)\left|\hat{U}-U^{*}\right|+\gamma\left|U_{n}-U^{*}\right|+\gamma h\left|f(\hat{U})-f\left(U^{*}\right)\right| \\
& \leq(1-\gamma)\left|\hat{U}-U^{*}\right|+\gamma\left|U_{n}-U^{*}\right|+\gamma h L\left|\hat{U}-U^{*}\right| \\
& =(1-\gamma+\gamma h L)\left|\hat{U}-U^{*}\right|+\gamma\left|U_{n}-U^{*}\right|
\end{aligned}
$$

Now

$$
\begin{aligned}
\left|\hat{U}-U^{*}\right| & \leq\left|U_{n}-U^{*}\right|+h\left|f\left(U_{n}\right)-f\left(U^{*}\right)\right| \\
& \leq(1+h L)\left|U_{n}-U^{*}\right| .
\end{aligned}
$$

Combining these two inequalities we get:

$$
\left|U_{n+1}-U^{*}\right| \leq\left(1+h L+\gamma h^{2} L^{2}\right)\left|U_{n}-U^{*}\right|
$$

Let $E_{n}=\left|U_{n}-U^{*}\right|, \sigma=\left(1+h L+\gamma h^{2} L^{2}\right)$, then $E_{n+1} \leq \sigma E_{n} \leq \sigma^{2} E_{n-1} \leq$ $\ldots \leq \sigma^{n} E_{1}$, where $E_{1}=\left|U_{1}-U^{*}\right|$ is the error at $t=t_{1}$. If the method is strictly stable $\sigma<1$ and $\lim _{n \rightarrow \infty} E_{n}=0$. Thus if this method is strictly stable, it must be able to solve a steady-state model.

In [1] several stability contours were drawn in the complex plane with $z=$ $\lambda h$, where $\lambda$ is complex. These also exhibit better stability properties of Charlie's predictor-corrector.

\section{APPLICATIONS TO PARTIAL DIFFERENTIAL EQUA- TIONS}

\subsection{Linear Inviscid Burgers' Equation}

$$
\begin{aligned}
& u_{t}+c u_{x}=0, \quad 0<x<1, t>0, \\
& u(x, 0)=f(x), \\
& u(0, t)=\mu(t) .
\end{aligned}
$$

Let us approximate $u_{t}$ by a forward difference formula and $u_{x}$ by a backward difference formula. Then Charlie's algorithm is

$$
\begin{aligned}
& \hat{U}_{j}=U_{j}^{n}-\alpha\left(U_{j}^{n}-U_{j-1}^{n}\right) j=1,2, \ldots J \\
& U_{j}^{n+1}=(1-\gamma) \hat{U}_{j}+\gamma\left\{U_{j}^{n}-\alpha\left(\hat{U}_{j}-\hat{U}_{j-1}\right)\right\} \quad j=1,2, \ldots J
\end{aligned}
$$

where $U_{j}^{n}=U\left(x_{j}, t_{n}\right)$ is the value of the grid-function $U$ at $x=x_{j}$ and $t=t_{n}$, $\gamma$ is the convex parameter and $\alpha=c \Delta t / \triangle x$.

Fourier Stability Analysis: Let

$$
U=\zeta^{n} e^{i \beta j h}
$$


Substituting $u$ in the predictor we get $\hat{U}=P Q$ where $P=\zeta^{n} e^{i \beta j h}, Q=$ $\left(1-\alpha+\alpha e^{-i \beta h}\right)$. Substituting this in the corrector and simplifying, we get $\zeta=1-\alpha(1-\exp (-i \beta h))+\gamma \alpha^{2}(1-\exp (-i \beta h))^{2}$. If we choose $\gamma=0.25$, $\zeta=\left(1-0.5 \alpha(1-\exp (-i \beta h))^{2}\right.$. For stability $|\zeta| \leq 1$. This gives $0<0.5 \alpha(1+$ $\cos \beta h) \leq(1+\cos \beta h)$ which is satisfied if:

$$
0<\alpha \leq 2 \quad \text { or } \quad \triangle t \leq 2 \triangle x / c .
$$

If $\gamma=0, \Delta t \leq \triangle x / c$. Thus Charlie's algorithm has increased the time-steps by a factor of 2 . These results have been verified computationally.

\subsection{Heat Conduction Equation}

$$
\begin{aligned}
& u_{t}=\nu u_{x x}, \quad 0<x<1, \quad 0<t \leq T, \\
& u(x, 0)=f(x), \quad x \in[0,1], \\
& u(0, t)=g_{1}(t), \quad u(1, t)=g_{2}(t), \quad 0 \leq t \leq T .
\end{aligned}
$$

Let $u_{t}$ be approximated by a forward difference formula and $u_{x x}$ be approximated by the central difference formula. Charlie's formula for the finite difference solution of the heat conduction equation is:

$$
\begin{aligned}
& \hat{U}=U_{j}^{n}+b\left(U_{j+1}^{n}-2 U_{j}^{n}+U_{j-1}^{n}\right) \quad j=1,2, \ldots J \\
& U_{j}^{n+1}=(1-\gamma) \hat{U}_{j}+\gamma\left(U_{j}^{n}+b\left(\hat{U}_{j+1}-2 \hat{U}_{j}+\hat{U}_{j-1}\right)\right) \quad j=1,2, \ldots J
\end{aligned}
$$

where $b=\nu \triangle t / \triangle x^{2}$. Following the same procedure as before, one can find, $\zeta=1+\theta+\gamma \theta^{2}$, where $\theta=-4 b \sin ^{2}(\beta h / 2)$. If we choose $\gamma=1 /(4 b)$, then the stability criterion: $|\zeta| \leq 1$ reduces to $0 \leq b \sin ^{2} \beta h \leq 2$. Hence the largest value of $b$ is 2 . Hence $\Delta t_{\max }=2(\triangle x)^{2} / \nu$. If $\gamma=0, \Delta t_{\max }=$ $(\triangle x)^{2} /(2 \nu)$. Charlie's algorithm has increased the conventional $\triangle t_{\max }$ used by most explicit finite difference schemes by a factor of 4 . This has also been verified by computer experimentation.

\subsection{Linear Burgers' Equation}

$$
\begin{aligned}
& u_{t}+c u_{x}=\nu u_{x x}, \\
& u(x, 0)=f(x), \quad x \in[0,1] \\
& u(0, t)=g_{1}(t) u(1, t)=g_{2}(t) t \in[0, T] .
\end{aligned}
$$

Let $u_{t}$ be approximated by a forward difference operator and $u_{x}$ and $u_{x x}$ be approximated by central differences. Then Charlie's algorithm is:

$$
\hat{U}_{j}=U_{j}^{n}-0.5 a\left(U_{j+1}^{n}-U_{j-1}^{n}\right)+b\left(U_{j+1}^{n}-2 U_{j}^{n}+U_{j-1}^{n}\right), \quad j=1,2, \ldots J
$$




$$
\begin{aligned}
U_{j}^{n+1}= & (1-\gamma) \hat{U}_{j}+\gamma\left\{U_{j}^{n}-0.5 a\left(\hat{U}_{j+1}-\hat{U}_{j-1}\right)\right. \\
& \left.+b\left(\hat{U}_{j+1}-2 \hat{U}_{j}+\hat{U}_{j-1}\right)\right\}, \quad j=1,2, \ldots J
\end{aligned}
$$

where $0<\gamma<1, a=c \triangle t / \triangle x$ and $b=\nu \triangle t / \triangle x^{2}$. For the stability analysis, following the same procedure as before, we get:

$$
\zeta=1+z+\gamma z^{2}
$$

where $z=2 b(-1+\cos \beta h)-i a \sin \beta h$. Here $z$ being complex, the stability contours given in [1] should be used to compute $\Delta t$ from a given $\Delta x$ when $\gamma$ is given.

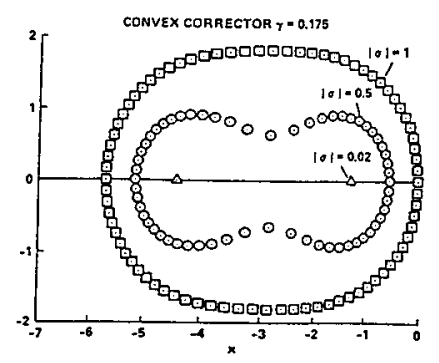

Figure 2. The stability contours.

Let us consider $\gamma=0.175$ (fig. 2). Then for stability $|\operatorname{Re} z| \leq 5.5$, giving $\Delta t_{\max }=1.38 \triangle x^{2} / \nu$. This is significantly larger in comparison with the conventional $\triangle t_{\max } \leq \triangle x^{2} /(2 \nu)$.

\section{NONLINEAR MODELS}

For nonlinear models, one must do a local linearization. However if the model is mildly nonlinear as in the case of Burgers' Equation or Euler's Equation or Navier-Stokes equation and we are primarily interested in the steady-state solution, then Charlie's algorithm is fruitful. In this regard, the Shock-Tube problem is very convenient. Let us discuss this now. The model is described by:

$$
w_{t}+F(w)_{x}=0,
$$

where $w=\left(\begin{array}{lll}\rho & \rho u & e\end{array}\right)^{T}, F(w)=\left(\begin{array}{lll}a & b & c\end{array}\right)^{T}, a=\rho u, b=(\gamma-1) e+$ $(3-\gamma) / 2) \rho u^{2}, e=\gamma e u-((\gamma-1) / 2) \rho u^{3}$. $\rho$ is density, $u$ is velocity, $p$ is pressure, $e$ is total energy per unit volume, given by $e=\rho \epsilon+\frac{u^{2}}{2}, \epsilon$ is internal energy per unit mass. For a perfect gas, $p$ is given by $p=(\gamma-1)\left(e-\rho u^{2} / 2\right)$, $\gamma=1.4$. 
Let two gases, separated by a diaphragm be in equilibrium in a tube. Let their densities be unequal. If the diaphragm is impulsively broken, the gas molecules start mixing. This phenomenon is often referred to as the shocktube problem. Here the following initial conditions are considered: $\rho=1$, $u=0, e=1 /(\gamma-1)$ for $0 \leq x \leq 1.9$ and $\rho=0.1, u=0, e=0.1 /(\gamma-1)$ for $1.9<x \leq 5$. The gas molecules start mixing and start settling down.

Charlie's algorithm, applied in this case, consists of the following steps:

$$
\begin{array}{ll}
\hat{w}_{j} & =w_{j}^{n}+(\triangle t / 2 \triangle x)\left(F_{j-1}^{n}-F_{j+1}^{n}\right) \\
w_{j}^{n+1} & =(1-\theta) \hat{w}_{j}+\theta\left\{w_{j}^{n}+(\triangle t / 2 \triangle x)\left(\hat{F}_{j-1}-\hat{F}_{j+1}\right)\right\} .
\end{array}
$$

Here $\theta$ is the convex parameter. For the first equation (conservation of mass) $\theta=0.15$, for the equation of motion (conservation of momentum) $\theta=0.25$, for the equation of energy $\theta=0.5$. Also, $\triangle x=0.0125$, and $\triangle t=0.008$.

These give CFL No. $=1.5$. In fig. 3 , fig. 4 and fig. 5 , density, pressure

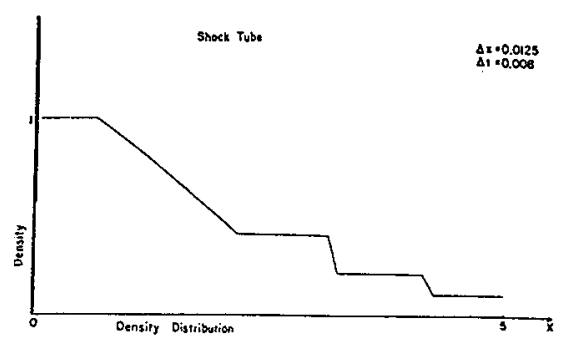

Figure 3. The density distribution.

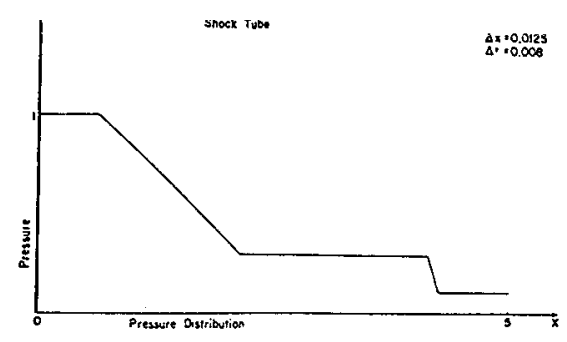

Figure 4. The pressure distribution.

and velocity distributions are shown. These are standard results which match perfectly with the findings of the others $[4,5]$. 


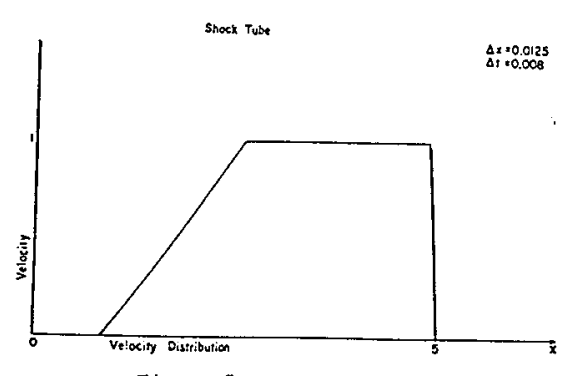

Figure 5. The velocity distribution.

\section{FLUX-VECTOR SPLITTING}

An interesting model (theoretical) is chosen here where in the flow field there is an interaction between a moving shock and a decaying expansion shock. The model is described by: $u_{t}+u u_{x}=\nu u_{x x}$, at $t=0, u=1$ if $0 \leq x \leq$ $0.05, u=-0.5$ for $0.05 \leq x<0.25, u=0.5$, if $0.25 \leq x<0.375$, else $u=-0.5$. Here Charlie's algorithm is combined with Flux-Vector splitting (at the suggestion of Warming [6]). Thus

$$
\begin{gathered}
\hat{U}_{j}=U_{j}^{n}+a\left\{\left(U_{j+1}^{n}-\left|U_{j+1}^{n}\right|\right) U_{j+1}^{n}+2 U_{j}^{n}\left|U_{j}^{n}\right|-\left(U_{j-1}^{n}+\left|U_{j-1}^{n}\right|\right) U_{j-1}^{n}\right\} \\
+b\left(U_{j+1}^{n}-2 U_{j}^{n}+U_{j-1}^{n}\right) \\
U_{j}^{n+1}=(1-\gamma) \hat{U}_{j}+\gamma\left(U_{j}^{n}+a\left\{\left(\hat{U}_{j+1}-\left|\hat{U}_{j+1}\right|\right) \hat{U}_{j+1}+2 \hat{U}_{j}\left|\hat{U}_{j}\right|\right.\right. \\
\left.\left.-\left(\hat{U}_{j-1}+\left|\hat{U}_{j-1}\right|\right) \hat{U}_{j-1}\right\}+b\left(\hat{U}_{j+1}-2 \hat{U}_{j}+\hat{U}_{j-1}\right)\right)
\end{gathered}
$$

where $a=-0.25 \triangle t / \triangle x, b=\nu \triangle t / \triangle x^{2}$. The results are shown in fig. 6 .

Clearly we see that the incoming shock, overcomes the expansion shock and moves on. Here $\triangle t=0.0035, \triangle x=0.0025, \gamma=0.125$ and $\nu=0.0001$. There are 400 points on the $x$-axis and 1000 time-steps are considered for computation.

\section{CONCLUSION}

This possibly one of the simplest algorithms to solve partial differential equations. It requires no matrix computation. It is a self-starter and in comparison with other similar methods which may be found in the reference [2], it exhibits far better stability property. Furthermore, if this algorithm is combined with flux-vector splitting, the shocks become crisp. Thus it may be safely concluded that the present algorithm could be quite useful to solve partial differential equations numerically. 


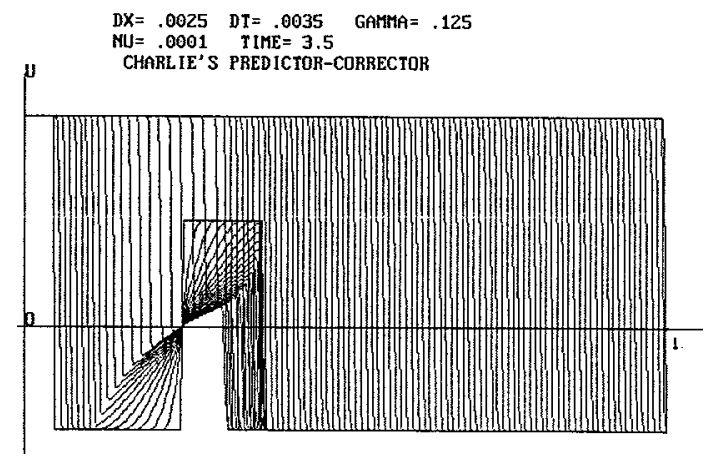

Figure 6. An interaction between a moving shock and a decaying expansion shock.

\section{REFERENCES}

[1] S.K. Dey and Charlie Dey. An Explicit Predictor-Corrector Solver with Applications to Burgers' Equation. In: NASA Technical Memo 84402, NASA-Ames Research Centre, Moffett Field, CA, Sept. 1983.

[2] D.A. Anderson, J.C. Tannehill and R.H. Pletcher. Computational Fluid Mechanics and Heat Transfer. Hemisphere Publishing Corporation, 1984.

[3] S.K. Dey. A Vectorized Predictor/Corrector Algorithm for Numerical Solution of Differential Equations. In: Proc. 14th IMACS World Congress on Computational \& Appd. Math., July 1994, Proc. 14th IMACS World Congress on Computational \&S Appd. Math. 3, 1994, 1994, 1206 - 1208.

[4] S.K. Dey. Numerical Solution of Euler's Equation by Perturbed Functionals. Lectures in Appd. Math., 22, 1985, 113 - 128 American Math. Society.

[5] P.L. Roe. Approximate Riemann Solvers, Parameter Vectors and Difference Schemes. J. Comp. Physics, 43, 1981.

[6] R. Warming . NASA-Ames Research Centre, Private Communication.

\section{NAUJA IŠREIKŠTINE் BAIGTINIŲ SKIRTUMU SCHEMA DIFERENCIALINIUূ LYGČIŲ DALINĖMIS IŠVESTINĖMIS SPRENDIMUI}

\section{S.K. DEY}

Daugelio išreikštųjų baigtinių skirtumų schemų stabilumo reikalavimai yra labai griežti. Darbe nagrinëjamas metodas, kuris jau buvo panaudotas sprendžiant skysčių tekèjimo uždavinius. Parodyta, kad skaitinio algoritmo realizacija yra ekonomiška ir šis metodas gali būti naudojamas sprendžiant plačią nestacionarių uždavinių klasę. Irodyta, kad naujosios išreikštinès baigtinių skirtumuc schemos stabilumo sąlyga yra silpnesnè nei daugelio kitu populiarių išreikštinių skirtumų schemų. Pateikti skaičiavimo eksperimento rezultatai, kai sprendžiama Burgerso lygtis ir Eulerio lygčių sistema. 